\title{
Khảo sát về năng lực sinh lợi của doanh nghiệp vừa và nhỏ ở Việt Nam
}

\author{
TS. Nguyễn Ninh Kiều
}

Phát Triển Kinh Tế, 2001 


\section{KHẢOSÁT VỀ} KHÅ VĬUVG

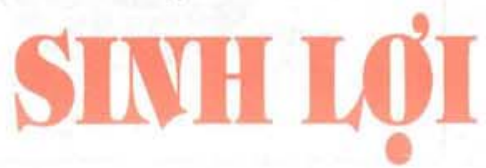

()

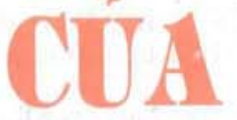

\section{DOAVH IGHIEP}

6
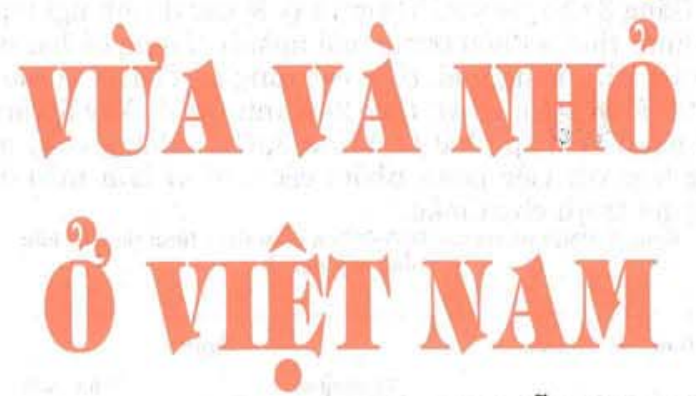

TS. NGUYỄN NINH KIỀU

\section{Giới thiệu}

Tại những nước phát triển như Mỹ, Canada, Anh và Úc, từ lâu khả năng sinh lợi đã được xem là rất quan trọng trong việc xác định sự thành công hay thất bại của một doanh nghiệp. Ở giai đoan thành lập, một doanh nghiệp có thể chưa sinh lợi vì phải đẩu tư và trang trải các chi phí thành lập. Khi doanh nghiệp phát đạt thì nó phải sinh lợi.

Do tầm quan trọng của khả năng sinh lợi, Edminster (1970) trong số nhiều nhà nghiên cứu trước đây đã cho rằng các doanh nghiệp nhỏ cần tập trung chú ý vào khả năng sinh lợi. Jen (1963) thấy rằng khả năng sinh lợi là một yếu tố xác định quan trọng vể rủi ro tín dụng của một doanh nghiệp nhỏ. Thomas và Evanson (1987) nhấn mạnh rằng mục tiêu của một doanh nghiệp không chỉ là tạo doanh thu, mà còn phải tạo ra lợi nhuận. Lợi nhuận là đặc biệt quan trọng vì nó cần thiết cho sự sống còn của doanh nghiệp. Khả năng sinh lợi thấp làm tắng thêm những vấn đề tăng vốn chậm vì nó dẩn đến những thu nhập kém hơn và đưa tới sự lệ thuộc vào nguồn vốn bên ngoài (Davidson và Dutia, 1991).

Tại VN, một nước đang phát triển, khả năng sinh lợi là đặc biệt quan trọng vì các doanh nghiệp vừa và nhỏ (DNV-N) gặp phải môi trường kinh doanh bất ồn và khó khăn trong việc tìm kiếm những nguồn vốn bên ngoài (Ebashi, Sakai và Takada, 1997; Vương, 1988).

Rõ ràng từ khi tiến hành đổi mới, khu vực tư nhân đã phát triển mau chóng về số lượng doanh nghiệp, tiền vốn và nhân công. Nếu lấy mức chuẩn là 0 vào năm 1991 , con số doanh nghiệp tư nhân và công ty TNHH đã tăng mau chóng lên tới 28.811 vào năm 1998 (Trần, 1998) và hầu hết là những DNV-N. Những doanh nghiệp này đã đóng góp đáng kể vào sự tăng trưởng GDP và tạo thêm công ăn việc làm. Vũ (1998) tóm lược những đóng góp của DNV-N như sau:

- cung cấp nhiều loại sản phẩm, chiếm $26 \%$ GDP và $30 \%$ sản lượng công nghiệp.

- tạo 4,5 triệu công ăn việc làm.

- huy động các tài nguyên chưa được sử dụng như đất đai, vốn, lao động và kŷ năng quản lý để phát triển sản xuất, và

- tăng lượng xuất khâu và giảm thâm hụt cán cân thương mại (giảm nhập siêu)

Bên cạnh những thành quả và đóng góp nói trên, DNV$\mathrm{N}$ tại $\mathrm{VN}$ hiệu đang đối mặt nhiều khó khăn nghiêm trọng như thiếu vốn để mở rộng sản xuất và đổi mới thiết bị và công nghệ, tình trạng kém năng suất và tính cạnh tranh, thiếu kinh nghiệm tiêp thị; quản lý sản xuất và tài chính (Ebashi, Sakai và Takada, 1997). Khảo sát này có mục tiêu là xác định xem các khó khăn đó có ảnh hưởng đến khả năng sinh lợi của các DNV-N hay không, đồng thời khái quát về khả năng sinh lợi của các DNV-N tại VN.

\section{2. Đo lường khả năng sinh lợi của các DNV-N}

Một trong những thuộc tính khó hình dung và đo lường nhất của một doanh nghiệp là khả năng sinh lợi (Ross, Westerfield và Jaffe, 1999). Trong ngũ nghĩa chung, những khoản lợi nhuận hạch toán là số chênh lệch giữa doanh thu và chi phí. Tuy nhiên, vấn đề với những thước đo khả năng sinh lời là ở chổ sự rủi ro chưa được tính đến. Trong ngữ nghīa kinh tế, một công ty là sinh lợi chỉ khi nào khả năng sinh lợi cúa nó cao hơn mức mà nhà đầu tư có thể kiếm được từ thị trường vốn. Ross và các tác giả khác (1999) đề xuất một số phương pháp để đo lường khả năng sinh lợi bao gồm tỉ lệ lợi nhuận, hay là tiền lãi bán hàng, lợi suất trền tích sản, và lợi suất trên vốn cổ phần.

Burns (1985) đo lường khả năng sinh lợi bằng cách sử dụng ba biến số biểu thị: lợi suất trên tổng tích sản, lợi suất trên tích sản thuần và lợi suất trên vốn cồ phần. Hutchinson, Meric và Meric (1988) dùng hai biến số, lợi suất trên doanh số và lợi suất trên vốn cổ phẩn, để đo lường khả năng sinh lợi, trong khi Cohen (1989) đề nghị bốn biến số: khả năng doanh lợi tích sản, lợi suất trên vốn cổ phần, tiền lãi thuâ̂n trên doanh số và lợi suất trên đầu tư. Nhìn chung, tùy theo mục đích của mình, các nhà nghiên cứu trên đã dùng nhiều biến số biểu thị khác nhau để đo lường khả năng sinh lợi. Tuy nhiên, ba biến số: lợi suất trên doanh số (ROS), lợi suất trên tích sản ( $\mathrm{ROA}$ ) và lợi suất trên vốn cổ phần ( $\mathrm{ROE}$ ) là được các nhà nghiên cứu sử dụng nhiều nhất để đo lường khả năng sinh lợi.

Các nhà nghiên cứu trước đây đã dùng nhiều tỷ suất khác nhau để đo lường khả năng sinh lợi tùy theo mục đích nghiên cứu. Bảng sau đây tóm lược các tỷ suất được các nhà nghiên cứu dùng để đo lường khả năng sinh lợi của các $\mathrm{DNV}-\mathrm{N}$, trong số các tỷ suất này, ROS, ROA và ROE là được sử dụng nhiều nhất.

Bảng 1: Cách do lường khả năng sinh lợi của các DNV-N

\begin{tabular}{|c|c|c|}
\hline $\begin{array}{l}\text { Nhà } \\
\text { nghiên cứu }\end{array}$ & Tỹ suất & Mục tiêu do lường hoặc tính toán \\
\hline Burns (1985) & $\begin{array}{l}\text { Lại suất trèn tống tích sản } \\
\text { lại suắt trên tích sản thuẳn } \\
\text { ROE }\end{array}$ & $\begin{array}{l}\text { Mức sử dụng tích sảı hỉu hiệu } \\
\text { Hiệu quả kinh doanh } \\
\text { Lợi suất cho cố dồng }\end{array}$ \\
\hline $\begin{array}{l}\text { Hutchinson, } \\
\text { Meric và } \\
\text { Meric (1988) }\end{array}$ & $\begin{array}{l}\text { ROS } \\
\text { ROA } \\
\text { ROE }\end{array}$ & 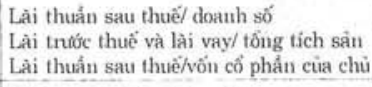 \\
\hline $\begin{array}{l}\text { Jaggi \& } \\
\text { Considine } \\
\text { (1990) }\end{array}$ & $\mathrm{ROA}$ & Lài doanh nghiẹp/tổng tích sân \\
\hline $\begin{array}{l}\text { Laitinen } \\
\text { (1992) }\end{array}$ & Lợi suẩt trễn dáu tư & Tỹ suăt lài trè̀ dắu tư \\
\hline $\begin{array}{l}\text { Meric và các } \\
\text { tác giả khác } \\
\text { (1997) }\end{array}$ & $\begin{array}{l}\text { ROS } \\
\text { ROA } \\
\text { ROE }\end{array}$ & 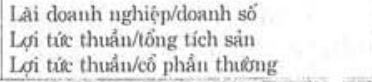 \\
\hline
\end{tabular}


Khả năng sinh lợi của DNV-N là một khái niệm trừu tượng. Có nhiều cách khác nhau để đo lường khả năng sinh lợi. Bài viết này giới hạn những thước đo khả năng sinh lợi của $\mathrm{DNV}$ $\mathrm{N}$ vào những tỷ suất ROS, ROA và ROE. Viêc giới hạn này là cần thiết để thu hẹ pham vi nghiên cứu và cũng phù hợp với những cách thức quản lý tài chính của DNV-N tai VN. Ngoài ra, trong bài viết này, khả năng sinh lợi được đinh nghĩa như một khái niệm so sánh. Một doanh nghiệp được coi là "sinh lợi" nếu nó tạo ra tiền lãi trung bình hàng năm lớn hơn lãi suất ngân hàng vốn không có rủi ro (ước lượng khoảng $5,4 \%$ vào giữa 2000 tại VN). Ngược lại, nếu lợi nhuận bình quân hàng năm của một doanh nghiệp không lớn hơn lãi suất không rủi ro thì doanh nghiệp đó "không sinh lợi". Những luận điểm cho định nghĩa về khả năng sinh lợi của $\mathrm{DNV}-\mathrm{N}$ nói trên được dựa trên những giả đinh sau:

- Thứ nhất, lãi suất tiền gửi tại các ngân hàng thương mại quốc doanh được coi là không có rủi ro vì được nhà nước bảo dảm.

- Thứ nhì, lãi suất không rủi ro này được coi là chi phí cơ hội của vốn, và $\mathrm{DNV}-\mathrm{N}$ phải tạo ra lợi nhuận bình quân hàng năm lớn hơn chi phí cơ hội, nếu không nó phải ngưng hoạt động và gửi tiền vào ngân hàng để hưởng lãi suất không rủi ro.

\section{Phương pháp nghiên cứu}

Công trình này sử dụng kỹ thuật lấy mẫu phân tầng với tỉ lệ 90 để chon mầu với một qui trình định trước để chọn mẫu. Dựa trên một danh sách các doanh nghiệp do Sở Kế hoach và đầu tư TP.HCM cung cấp, 14.424 DNV-N tai TP.HCM, gồm 5.170 doanh nghiệp sản xuất $(35,8 \%)$ và 9,254 doanh nghiệp thương mai $(64.2 \%)$ được chon ra làm đối tượng nghiên cứu. Một bộ mẫu gồm $400 \mathrm{DNV}-\mathrm{N}$ được chon ngẩu nhiên từ danh sách này để phỏng vấn. Ba mươi người phỏng vấn - là sinh viên của Khoa tài chính và Khoa kế toán của ĐHKT TP.HCM- được tuyển mộ và huấn luyện về kỹ thuật tiếp xúc và phỏng vấn các $\mathrm{DNV}-\mathrm{N}$ đã chọn. Có 160 trong số $400 \mathrm{DNV}-\mathrm{N}$ này tham gia cuộc khảo sát, tỷ lệ đáp ứng là $40 \%$.

Sau khi xem xét các dữ liệu, có 10 trường hợp không sử dụng được và bị loại bỏ, không đưa vào phân tích. Kết quả là bộ mẫu gồm 150 DNV-N được dùng để phân tích trong công trình này. Phân loại các $\mathrm{DNV}-\mathrm{N}$ này theo ngành và hình thức sở hữu là như sau:

Bảng 2: Các DNV-N chọn làm mẫu phân theo ngành và hình thức sở hữu

\begin{tabular}{|l|r|r|}
\hline \multicolumn{1}{|c|}{ Phân loại } & \multicolumn{1}{c|}{ Số DNV-N } & \multicolumn{1}{c|}{ Tỹ lę̂ } \\
\hline NGÀNH & 99 & $66,0 \%$ \\
Thương mại & 51 & $34,0 \%$ \\
Sản xuất & & \\
HìnH THƯC SỞ HƯU & 40 & $26,7 \%$ \\
DN tư nhân & 105 & $70,0 \%$ \\
Công ty TNHH & 5 & $3 ; 3 \%$ \\
Công ty cồ phần & & \\
\hline
\end{tabular}

Bảng trên cho thấy trong số mẫu, $66 \%$ DNV-N là doanh nghiệp thương mại, và $34 \%$ là doanh nghiệp sản xuất, còn những ngành khác thì nằm ngoài cuộc khảo sát. Hình 1 và 2 mô tả rõ hơn sự phân loại này.

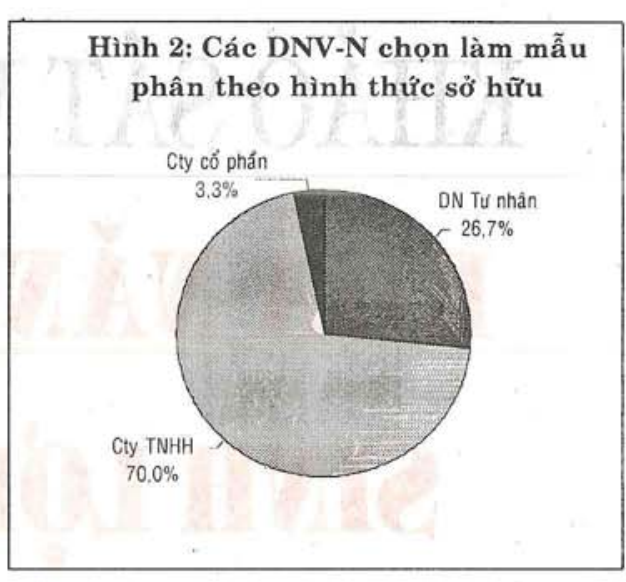

(Hình 1: Các DNV-N chọ làm mẫu phân theo ngành và Hình 2: Các DNV-N chọn làm mẫu phân theo hình thức sở hữu

Hình 2 mô tả có $70 \%$ các doanh nghiệp chọn làm mẫu là các công ty TNHH; $26,7 \%$ là doanh nghiệp tư nhân và $3,3 \%$ là các công ty cổ phần. Những bộ phận này không khác biệt lắm với những bộ phân được dự trù trong quá trình chọn mẫu. Nên công trình khảo sát vẫn được bảo đảm rằng số mẫu phản ảnh chính xác toàn khối DNV-N theo cơ sở các tiêu chuẩn phân tầng chọn mẫu.

Bảng 3 cho thấy số lượng và tỷ lệ các doanh nghiệp chia theo hình thức sở hữu trong mỗi ngành. Trong cả hai ngành sản xuất và thương maii, tỷ lệ các công ty $\mathrm{TNHH}$ là cao nhất (65,7\% và $78,4 \%$ lần lượt theo 2 ngành trên) và tỷ lệ các công ty cổ phần là thấp nhất $(3,0 \%$ và $3,9 \%)$. Những tỷ lệ này là tương hợp với việc phân nhóm các đơn vị làm mẫu dự trù trong qui trình chọn mẫu.

Bảng 3: Phân nhóm các DNV-N làm mẫu theo hình thức sở hữu trong mổi ngành

\begin{tabular}{|l|c|c|c|c|}
\hline \multirow{2}{*}{ Hình thức sở hữu } & \multicolumn{4}{|c|}{ Ngành } \\
\cline { 2 - 5 } & \multicolumn{2}{|c|}{ Thương mai } & \multicolumn{2}{c|}{ Sản xuất } \\
\hline & Số DN & $\%$ & Số DN & $\%$ \\
\hline Doanh nghiệp tư nhân & 31 & $31,3 \%$ & 9 & $17,6 \%$ \\
Cóng ty TNHH & 65 & $65,7 \%$ & 40 & $78,4 \%$ \\
Công ty cố phắn & 3 & $3,0 \%$ & 2 & $3,9 \%$ \\
\hline
\end{tabular}

Bảng 4: Đặc điểm kinh doanh của các $\mathrm{DNV}-\mathrm{N}$ làm mẫu

\begin{tabular}{|c|c|c|c|}
\hline Đặc điểm & & Số DN & $\%$ \\
\hline Thâm niên kinh doanh & $\begin{array}{l}\text { dưới } 2 \text { nà̀m } \\
2-5 \text { nāum } \\
6-10 \text { năm } \\
\text { hơn } 10 \text { năm }\end{array}$ & $\begin{array}{r}47 \\
55 \\
42 \\
6 \\
\end{array}$ & $\begin{array}{r}31,3 \% \\
36,7 \% \\
28,0 \% \\
4,0 \%\end{array}$ \\
\hline Doanh số hàng năm & $\begin{array}{l}\text { dưởi } 5 \text { tỷ VND } \\
5-30 \text { tỷ VND } \\
31-50 \text { tỳ VND } \\
\text { hơn } 50 \text { tỷVND }\end{array}$ & $\begin{array}{r}110 \\
33 \\
2 \\
5 \\
\end{array}$ & $\begin{array}{r}73,3 \% \\
22,0 \% \\
1,3 \% \\
3,3 \% \\
\end{array}$ \\
\hline Tống tích sản & $\begin{array}{l}\text { dưới } 5 \text { tỷyND } \\
5-10 \text { tỳ VND } \\
\text { trèn } 10 \text { tý VND }\end{array}$ & $\begin{array}{r}135 \\
8 \\
\quad 7 \\
\end{array}$ & $\begin{array}{r}90,0 \% \\
5,3 \% \\
4,7 \%\end{array}$ \\
\hline Lao dộng & $\begin{array}{l}\text { 1-10 nhân công } \\
11-30 \text { nhân công } \\
31-50 \text { nhân công } \\
51-100 \text { nhân công } \\
\text { 101-250 nhân công } \\
\text { hơn } 250 \text { nhân cồng }\end{array}$ & $\begin{array}{r}66 \\
52 \\
8 \\
10 \\
10 \\
2\end{array}$ & $\begin{array}{r}44,6 \% \\
35,1 \% \\
5,4 \% \\
6,8 \% \\
6,8 \% \\
1,4 \%\end{array}$ \\
\hline
\end{tabular}

Bảng 4 trình bày tổng quát các đặc điểm của các $\mathrm{DNV}-\mathrm{N}$ làm mẫu. Có $96 \%$ các doanh nghiệp này hoạt động chưa đầy 10 năm; chỉ có $4 \%$ được trên 10 năm. Về qui mô, $92 \%$ các doanh nghiệp có dưới 100 nhân công; $95 \%$ có tổng tích sản dưới 10 tỷ (với tỷ giá là $14.000 \mathrm{VND} / 1 \mathrm{USD}$ ). Những doanh 
nghiệp này đạt tiêu chuẩn trong định nghĩa DNV-N tại VN. Ngoài ra, $73,3 \%$ các DNV-N có doanh số dưới 5 tỷं; $22 \%$ có doanh số từ 5 đến 30 tỷ, và chưa tới $5 \%$ đạt mức trên 30 tỷ.

\section{Kết quả khảo sát}

a. Tổng quan về khả năng sinh lợi

Như đã nói, một doang nghiệp được gọi là "sinh lợi" khi tao được lợi nhuân bình quân hàng năm cao hơn lãi suất không rủi ro (khoảng 5,4\% tại VN thập niên 1990). Lợi nhuận bình quân hàng năm được tính trung bình từ ba tỷ suất: ROS, ROA và $R O E$. Lãi suất không rủi ro là lãi suất tiền gửi tại các ngân hàng thương mai quốc doanh $(0,4 \%)$ tháng, tức $5,4 \%$ /năm ở thời điểm 2000 ).

Dựa trên định nghĩa về khả năng sinh lợi nói trên, bảng 5 cho thấy 99 trong số 150 DNV-N $(66 \%)$ là có sinh lợi. Số $34 \%$ còn lại không sinh lợi. Bảng 5 trình bày qui mô lợi nhuận hàng năm của các DNV-N: có $10 \%$ đat lợi nhuân trên 500 triệu; $50 \%$ đạt từ 50 đến 300 triệu; và $18 \%$ đạt dưới 50 triệu. Qui mô lợi nhuân này là nhỏ bé so với các nước khác vì qui mô của lực lượng lao động và tổng tích sản của các doanh nghiệp đều nhỏ.

Bång 5: Tống quan vể khả năng sinh lợi

\begin{tabular}{|c|c|c|}
\hline Doanh lợi & Số DN & $\%$ \\
\hline 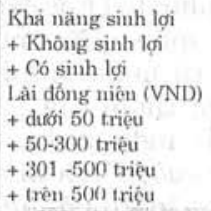 & $\begin{array}{l}51 \\
99 \\
\\
27 \\
74 \\
33 \\
16\end{array}$ & $\begin{array}{l}34,0 \% \\
66,0 \% \\
18,0 \% \\
49,3 \% \\
22,0 \% \\
10,7 \%\end{array}$ \\
\hline
\end{tabular}

Trên đây chỉ là một tổng quan về khả năng sinh lợi của các DNV-N. Phân tích cụ thể hơn dưới đây sẽ cho phép một cái nhìn thấu đáo hơn.

b. Khả năng sinh lợi và cấu trúc doanh nghiệp

Phần này sẽ tìm mối tương quan giữa cấu trúc doanh nghiêp và khả năng sinh lợi để xem loai doanh nghiệp nào là sinh lợi. Bảng 6 trình bày mối tương quan này và cho thấy các doanh nghiệp sản xuất sinh lợi hơn các doanh nghiệp thưong mại: các doanh nghiệp sản xuất chiếm $34 \%$ số doanh nghiệp được khảo sát nhưng ho là $36,4 \%$ của nhóm có sinh lợi; trong khi doanh nghiệp thương mại chiếm $66 \%$ số được khảo sát nhưng chỉ chiếm $63,6 \%$ của nhóm doanh nghiêp có sinh lơi. Ở phía ngược lại, các doanh nghiệp thương mại chiếm $70,6 \%$ của nhóm không sinh lợi còn các doanh nghiệp sản xuất chiếm $29,4 \%$.

Bảng 6: Tương quan giữa khả nãng sinh lợi và loại hình doanh nghiệp

\begin{tabular}{|c|c|c|c|c|c|c|}
\hline \multirow[t]{2}{*}{ Loại hình } & \multicolumn{2}{|c|}{ Sinh lợi } & \multicolumn{2}{|c|}{ Không sinh lợi } & \multicolumn{2}{|c|}{ Tống cộng } \\
\hline & Số DN & fs & Só DN & $\%$ & Sö́ DN & $\%$ \\
\hline $\begin{array}{l}\text { NGANAH } \\
\text { - Thương mại } \\
\text { - Sän xuất }\end{array}$ & $\begin{array}{l}36 \\
15\end{array}$ & $\begin{array}{l}70,6 \\
29,4\end{array}$ & $\begin{array}{l}63 \\
36\end{array}$ & $\begin{array}{l}63,6 \\
36,4\end{array}$ & $\begin{array}{l}99 \\
51\end{array}$ & $\begin{array}{l}66,0 \\
34,0\end{array}$ \\
\hline - ('öng & 51 & 100.0 & 99 ! & 100,0 & 150 . & 100,0 \\
\hline 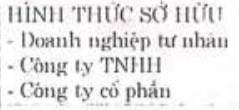 & $\begin{array}{r}8 \\
40 \\
3\end{array}$ & $\begin{array}{r}15,7 \\
78,4 \\
5,9\end{array}$ & $\begin{array}{r}32 \\
65 \\
2\end{array}$ & $\begin{array}{r}32,3 \\
65,7 \\
2,0 \\
\end{array}$ & $\begin{array}{r}40 \\
105 \\
5\end{array}$ & $\begin{array}{r}26,7 \\
70,0 \\
3,3 \\
\end{array}$ \\
\hline - Công & 51 & 100,0 & 99 & 100,0 & 150 & 100,0 \\
\hline
\end{tabular}

Măt khác, bảng 6 cũng cho thấy các doanh nghiệp tư nhân sinh lợi hơn các công ty $\mathrm{TNHH}$ và cổ phần. Về cấu trúc, các doanh nghiệp tư nhân, công ty TNHH và công ty cổ phần chiếm lần lượt $26,7 \% ; 70,0 \%$ và $3,3 \%$ số doanh nghiệp được khảo sát nhứng tỷ lệ có lải lẩn lược của chúng là $32,3 \% ; 65,7 \%$ và $2,0 \%$. Như vây, nhóm công ty TNHH chiếm $70 \%$ trong tổng số, nhưng chỉ chiếm $65,7 \%$ trong số doanh nghiệp có lãi, trong khi hai con số này của nhóm doanh nghiệp tư nhân là $26,7 \%$ và $32,3 \%$.

c. Khả năng sinh lợi và qui mô doanh nghiêp

Phần này phân tích mối tương quan giữa khả năng sinh lợi và qui mô doanh nghiệp để thấy ở qui mô nào thì doanh nghiệp thường có lãi. Bảng 7 cho thấy doanh nghiệp qui mô nhỏ về tổng tích sản, doanh số hàng năm và lức lương lao động thì thường có lâi hơn những doanh nghiệp lớn hơn. Những dữ liệu này ủng hộ quan điểm "nhỏ thì có lãi hơn."

Bảng 7:Tương quan giữa khả năng sinh lợi và qui mô doanh nghiệp

\begin{tabular}{|c|c|c|c|c|c|c|}
\hline \multirow{2}{*}{ Qui mô } & \multicolumn{2}{|c|}{ Sinh lợi } & \multicolumn{2}{|c|}{ Không sinh lợi } & \multicolumn{2}{|c|}{ Tồng công } \\
\hline & Sớ DN & $\mathrm{s}$ & Só DN & $\%$ & Só́ DN & $\%$ \\
\hline $\begin{array}{l}\text { Tống tích sảı } \\
\text { - Dưới } 5 \text { tỷ } \\
-5 \text { tới } 10 \text { tỳ } \\
\text { - Hơn } 10 \text { tỳ }\end{array}$ & $\begin{array}{r}45 \\
3 \\
3 \\
\end{array}$ & $\begin{array}{r}88,2 \\
5,9 \\
5,9 \\
\end{array}$ & $\begin{array}{r}90 \\
5 \\
4\end{array}$ & $\begin{array}{r}90,9 \\
5,1 \\
4,0 \\
\end{array}$ & $\begin{array}{r}135 \\
8 \\
7 \\
\end{array}$ & $\begin{array}{r}90,0 \\
5,3 \\
4,7\end{array}$ \\
\hline $\begin{array}{l}\text { Doanh số hàng uàm } \\
- \text { Dưới } 5 \text { tyे } \\
-5 \text { tới } 30 \text { tý } \\
-31 \text { tới } 50 \text { ty̆ } \\
\text { - Trên } 50 \text { tỹ }\end{array}$ & $\begin{array}{r}36 \\
13 \\
1 \\
1\end{array}$ & $\begin{array}{r}70,6 \\
25,5 \\
2,0 \\
2,0 \\
\end{array}$ & $\begin{array}{r}74 \\
20 \\
1 \\
4\end{array}$ & $\begin{array}{r}74,7 \\
20,2 \\
1,0 \\
4,0\end{array}$ & $\begin{array}{r}110 \\
33 \\
2 \\
5\end{array}$ & $\begin{array}{r}73,3 \\
22,0 \\
1,3 \\
3,3\end{array}$ \\
\hline $\begin{array}{l}\text { Lao đớng (số nhân công) } \\
-1 \text { tới } 10 \\
\text { - } 11 \text { tới } 30 \\
\text { - } 31 \text { tới } 50 \\
\text { - } 51 \text { tới } 100 \\
\text { - } 101 \text { tới } 250 \\
\text { - Trên } 250\end{array}$ & $\begin{array}{r}18 \\
22 \\
2 \\
5 \\
4\end{array}$ & $\begin{array}{r}35,3 \\
43,1 \\
3,9 \\
9,8 \\
7,8\end{array}$ & \begin{tabular}{r|r}
48 & \\
30 & \\
6 & \\
5 & \\
6 & \\
2 &
\end{tabular} & $\begin{array}{r}49,5 \\
30,9 \\
6,2 \\
5,2 \\
6,2 \\
2,1\end{array}$ & \begin{tabular}{r|r}
66 \\
52 \\
8 \\
10 \\
10 \\
10 \\
2
\end{tabular} & \begin{tabular}{r||}
44,6 \\
35,1 \\
5,4 \\
6,8 \\
6,8 \\
1,4
\end{tabular} \\
\hline
\end{tabular}

\section{Kết luân}

Những kết quả mô tả trên về khả năng sinh lợi của các DNV-N cho thấy 99 trong số 150 doanh nghiệp được khảo sát (tức $66 \%$ ) là có sinh lãi và số $34 \%$ còn lại không sinh lãi, nghīa là, họ không thể kiếm lãi cao hơn lãi suất không rủi ro. Qui mô lãi đồng niên của các DNV-N ở VN không cao so với các nước khác vì qui mô tích sản, doanh số và lao động đều nhỏ. Trong mối tương quan với ngành và hình thức sở hữu, cuộc khảo sát tìm ra những kết quả sau:

- Tỷ lệ doanh nghiệp có lãi trong ngành sän xuất cao hơn tỷ lệ đó trong ngành thương mại.

- Các doanh nghiệp tư nhân thường sinh lợi hơn các công ty TNHH hoặc cổ phẩn.

- Các doanh nghiệp có qui mô nhỏ thường dễ sinh lợi hơn các doanh nghiệp có qui mô lớn hơn घ

\section{Tài liệu tham khảo}

- Burns, P. (1985), Financial Characteristics of Small Companies in the UK, Cranfield School of Management

- Cohen, W.A. (1989), The Entrepreneur and Small Business Financial Problem Solver, John Wiley \& Son, New York

- Davidson III, W.N., và Dutia,D. (1991) "Debt, Liquidity and Profitability Problems in Small Firms" trong Entrepreneurship: Theory and Practice, Fall.

Ebashi, M., Sakai,H., và Takada, N. (1997), Development Policy on SMEs and Supporting Industries in Vietnam.

- Hutchinson, P. Meric,I., và Meric, G. (1988), "The Financial Characteristics of Small Firms Which Acgieve Quotation on the UK Unlisted Securities Market", Journal of Business Finance and Accounting, 15(1). - Jen, F.C. (1963), "The Determinants of the Degree of Insufficiency of Bank Credit to Small Business", Journal of Finance, 18

- Meric, I. et al. (1997), "A Comparison of the Financial Characteristics of U.S. and Japanese Chemical Firms", Multinational Business Review. Fall.

- Ross, S.A., Westerfield,R.W., và Jaffe,J. (1999), Corporate Finance, Irwin and McGraw-Hill, Boston.

- Thomas,J. và Evanson, R.V. (1987), "An Emperical Investigation of Association Between Financial Ratio Use and Small Business Success", Journal of Business and Accounting, 14(4)

- Tran, Q.N. (1998), Foreign Investment and SMEs in Vietnam, nxb Thống kê, Hà Nội.

- Vu, T.L. (1998), Developing SMEs in Vietnam: Present Situation and Solutions, nxb Thống kê, Hà Nội.

- Vuong, Q.H. (1998), "SMEs to Play a Large Role in Private Sector", Vietnam Investment Review. 


\section{References}

Burns, P. (1985). Financial characteristics of small companies in the UK. Cranfield School of Management.

Cohen, W.A. (1989). The entrepreneur and small business financial problem solver. John Wiley \& Son, New York.

Davidson III, W.N., \& Dutia, D. (1991). Debt, liquidity and profitability problems in small firms. Entrepreneurship: Theory and Practices.

Ebashi, M., Sakai, H., \& Takada, N. (1987). Development policy on SMEs and supporting industries in Vietnam.

Hutchinson, P., Meric, I., \& Meric, G. (1988). The financial characteristics of small firms which achieve quotation on the UK unlisted securities market. Journal of Business Finance and Accounting, 15(1).

Jen, F.C. (1963). The determinants of the degree of insufficiency of bank credit to small business. Journal of Finance, 18.

Meric, I., et al. (1997). A comparison of the financial characteristics of U.S. and Japanese chemical firms. Multinational Business Review.

Ross, S.A., Westerfield, R.W., \& Jaffe, J. (1999). Corporate Finance. Irwin and McGrawHill, Boston.

Thomas, J., \& Evanson, R.V. (1987). An empirical investigation of association between financial ratio use and small business success. Journal of Business and Accounting, 14(4).

Tran, Q.N. (1998). Foreign Investment and SMEs in Vietnam. Nxb Thống kê, Hà Nội.

Vu, T.L. (1998). Developing SMEs in Vietnam: Present Situation and Solutions. Nxb Thống kê, Hà Nội.

Vuong, Q.H. (1998). SMEs to play a large role in private sector. Vietnam Investment Review. 